\title{
Disain Awal Kapal Ikan Berbahan Fiberglass Kapasitas 30 GT
}

\author{
Amir Marasabessy ${ }^{1}$, Ahmad Zayadi², Rusdy Hatuwe' ${ }^{1}$, Sri Sulasminingsih ${ }^{1}$ \\ ${ }^{1}$ Fakultas Teknik, UPN Veteran Jakarta, Jl.RS.Fatmawati No.1 Pondok Labu Jakarta Selatan \\ 12450 \\ ${ }^{2}$ Program Studi Teknik Mesin, Fakultas Teknik dan Sains Universitas Nasional Jakarta - 12520 \\ Korespondensi penulis: amir141161@gmail.com
}

\begin{abstract}
Abstrak. Selama ini dalam pembangunan kapal ikan 30 GT berbahan fiberglass oleh Kementrian Kelautan Perikanan ukuran pokok kapal selalu berbeda satu dengan lainnya, hal ini berdampak terhadap perbedaan penentuan besaran kecepatan dan besaran tenaga motor induk. Hal ini sebagai akibat dari perencanaan kapal yang tidak akurasi, jika besaran-besaran tersebut lebih besar dari yang direncanakan maka produksi kapal menjadi tidak ekonomis. Sebaliknya jika besaran tersebut secara lebih kecil dari yang direncanakan maka pihak pembangunan kapal akan dikenakan sanksi/ganti kerugian negara. Oleh sebab itu untuk perencanaan ukuran pokok kapal ikan 30 GT berbahan fiberglass pada tahapan preliminary design akan memperhatikan keakurasian dengan menggunakan program maxsurff. Pada makalah ini dilakukan perencanakan ukuran pokok kapal ikan 30 GT berbahan fiberglass yang akurasi. Metode yang digunakan dalam perencanaan ini adalah metode optimasi preliminary design dan optimation design approach serta metode statistik regresi linear. Berdasarkan hasil dan pembahasan, dengan menggunakan Microsoft Excel add-in solver diperoleh ukuran pokok kapal yang optimum yakni panjang $($ Loa $)=21 \mathrm{~m}$; Lebar $(\mathrm{B})=4 \mathrm{~m}$; Tinggi $(\mathrm{H})=1.8 \mathrm{~m}$; Sarat $(\mathrm{T})=1 \mathrm{~m}$ dan koefisien blok $(\mathrm{Cb})=0.5$. Minimizing the main engine effective power sebesar $110.67 \mathrm{~kW}$ (150.47 Hp).
\end{abstract}

Kata kunci: kapal ikan 30 GT, fiber glass, engine power.

\section{PENDAHULUAN}

Saat ini langkah konkrit pemerintah untuk pencegahan ilegal fishing yakni melakukan penangkapan fishing boat negara tetangga yang mengambil ikan secara ilegal di perairan wilayah Indonesia kemudian dilanjutkan dengan peneggelaman kapal, akan tetapi dengan perairan wilayah Indonesia yang begitu luas maka sangat dimungkinkan adanya ilegal fishing yang tidak diketahui. Berkaitan dengan hal ini maka perlu dilakukan pengawasan perairan wilayah Indonesia secara terintegrasi dan terpadu dengan melibatkan pihak-pihak yang terkait, diantaranya pengembangan dan pengadaan berbagai jenis fishing boat yang sangat dibutuhkan bagi para nelayan di berbagai wilayah di Indonesia agar selain dapat meningkatkan hasil tangkapan ikan juga sangat membantu dalam melakukan pengawasan perairan wilayah Indonesia.

Berkaitan dengan bahan yang digunakan untuk produksi fishing boat, bahan fiber glass lebih diunggulkan mengingat bahannya mudah diperoleh dipasaran, biaya produksinya sangat kompetitif dan tidak membutuhkan investasi yang besar dan proses produksinya cepat dengan mengacu pada perencanaan lines plan [1]. Hal ini jika dibandingkan dengan bahan baja, baik biaya produksi maupun perawatan sangat mahal dan membutuhkan investasi yang besar untuk proses produksi. Sedangkan bahan kayu, biaya produksinya sedikit lebih murah dari bahan fiber glass akan tetapi proses produksi dikerjakan oleh pengrajin kayu yang tidak menggunakan drawing desain sehingga sampai saat ini fishing boats berbahan kayu tidak memiliki sertifikat surat ukur parmanen yang dikeluarkan oleh pihak Syahbandar, dalam hal ini yang diperoleh adalah keterangan surat ukur sementara 
yang akan diperpanjang secara periodik. Selain itu dikhawatirkan akan terjadi pengrusakan hutan kayu dan ilegal loging [2].

Penelitian yang telah dilakukan sebelumnya adalah Desain Kapal Motor Pesiar Berbahan Fiberglass Tipe $\mathrm{V}_{21}$ Daya Angkut 8 Orang OBM $2 \times 85 \mathrm{HP}$, yang telah diterima sebagai HKI Desain Produk Industri berlaku dari 2014 s/d 2024 dengan nomor perdaftaran HKI.2-02-000003567. Selanjutnya Desain Prototipe Water Bus Double Hull Kapasitas Angkut 35 Orang berbahan Fiberglass dan Perencanaan Biaya Produksi, Konvensi Nasional ke 3 Badan Kejuruan Teknik Industri Persatuan Insinyur Indonesia (PII) 2018 ISBN 978-979-97907-3-7.

Selama ini dalam pembangunan kapal ikan 30 GT berbahan fiberglass oleh Kementrian Kelautan Perikanan dimana ukuran pokok kapal selalu berbeda satu dengan lainnya. Hal ini sebagai akibat dari perencanaan kapal yang tidak akurasi dan berdampak terhadap besaran-besaran gross tonnage, kecepatan kapal dan tenaga motor induk. Jika dalam perencanaan ukuran pokok kapal lebih besar maka produksi kapal menjadi tidak ekonomis, dengan kata lain pihak pembangunan kapal akan mengalami kerugian. Sebaliknya jika ukuran pokok kapal lebih kecil dari yang direncanakan maka pihak pembangunan kapal akan dikenakan sanksi (menggantikan kerugian negara). Oleh sebab itu untuk perencanaan ukuran pokok kapal ikan 30 GT berbahan fiberglass akan memperhatikan keakurasian dalam perencanaan. Sehingga tujuan dari penelitian ini adalah merencanakan ukuran pokok kapal ikan 30 GT berbahan fiberglass yang akurasi untuk memperoleh tenaga motor induk yang optimum.

\section{METODOLOGI PENELITIAN}

Metodologi penelitian dalam perencanaan ukuran pokok kapal ikan 30 GT berbahan fiberglass sebagaimana yang diperlihatkan pada gambar 1. Tahap 1, proses pengolahan data secara statistik untuk mendapatkan ukuran utama awal (initial dimension) meliputi pengumpulan data pembanding kapal ikan dengan ukuran 25-60 GT, proses regresi polinonial kuadratik [3]. Tahap 2, proses optimasi dengan Excel solver [4] untuk mendapatkan ukuran utama yang optimum, meliputi penentuan design variable, design parameter, design constraint dan objective function. Metode optimasi yang digunakan dalam perencanaan ukuran pokok kapal ikan 30 GT berbahan fiberglass bukan merupakan metode baru, sudah ada yang menggunakan metode tersebut namun digunakan untuk perencanaan kapal general cargo berbahan baja.
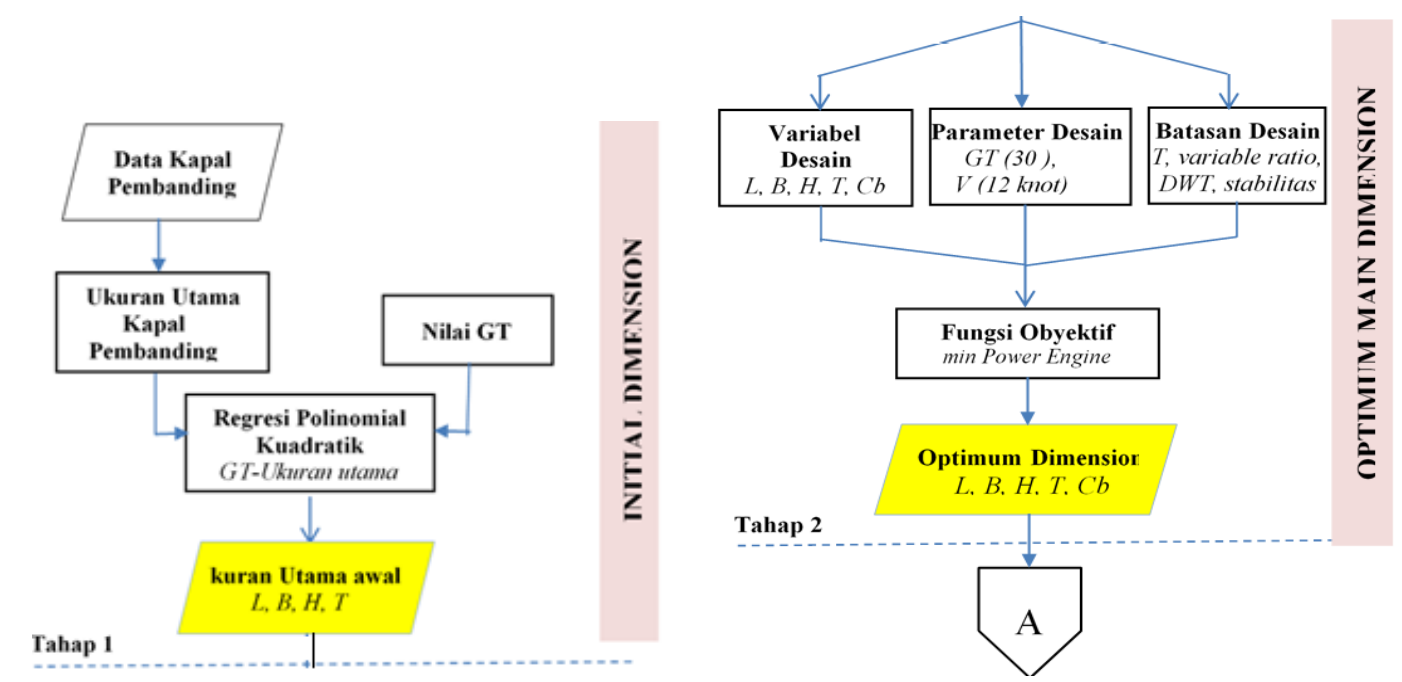

GAMBAR 1. Diagram metodologi “preliminary design" tahap 1 dan 2 [4]. 


\section{HASIL DAN PEMBAHASAN}

\section{Data Kapal Pembanding}

Data pembanding kapal ikan fiberglass yakni antara 20 GT sampai dengan 60 GT sesuai tabel 1 dan perbandingan ukuran utama pokok kapal sesuai tabel 2 .

TABEL 1. Data pembanding kapal ikan fiberglass.

\begin{tabular}{rccccc}
\hline No & GT (Estimasi) & LOA $(\mathbf{m})$ & $\mathbf{B}(\mathbf{m})$ & $\mathbf{H}(\mathbf{m})$ & $\mathbf{T}_{\text {DESIGN }}(\mathbf{m})$ \\
\hline 1 & 30.00 & 18.00 & 4.20 & 2.00 & 1.30 \\
2 & 30.00 & 16.00 & 5.50 & 2.00 & 1.30 \\
3 & 25.00 & 22.00 & 5.60 & 2.20 & 1.30 \\
4 & 30.00 & 23.00 & 5.50 & 2.20 & 1.30 \\
5 & 30.00 & 18.50 & 4.60 & 1.80 & 1.20 \\
6 & 60.00 & 29.50 & 5.60 & 2.20 & 1.60 \\
7 & 30.00 & 19.50 & 4.50 & 2.50 & 1.40 \\
8 & 20.00 & 16.00 & 3.30 & 1.70 & 0.70 \\
9 & 24.00 & 19.00 & 4.50 & 2.10 & 1.30 \\
10 & 30.00 & 18.00 & 4.20 & 2.50 & 1.50 \\
11 & 30.00 & 18.30 & 4.20 & 2.50 & 1.30 \\
12 & 30.00 & 19.50 & 4.30 & 1.70 & 0.80 \\
13 & 30.00 & 18.50 & 4.60 & 1.80 & 1.20 \\
14 & 20.00 & 16.00 & 3.30 & 1.70 & 0.70 \\
15 & 60.00 & 29.5 & 5.60 & 2.50 & 1.60 \\
\hline
\end{tabular}

TABEI 2. Perbandingan Ukuran Pokok Kapal.

\begin{tabular}{rcrrrr}
\hline No & L/B & \multicolumn{1}{c}{ L/H } & L/T & B/H & B/T \\
\hline 1 & 4.29 & 9.00 & 13.85 & 2.10 & 3.23 \\
2 & 2.91 & 8.00 & 12.31 & 2.75 & 4.23 \\
3 & 3.93 & 10.00 & 16.92 & 2.55 & 4.31 \\
4 & 4.18 & 10.45 & 17.69 & 2.50 & 4.23 \\
5 & 4.02 & 10.28 & 15.42 & 2.56 & 3.83 \\
6 & 5.27 & 13.41 & 18.44 & 2.55 & 3.50 \\
7 & 4.33 & 7.80 & 13.93 & 1.80 & 3.21 \\
8 & 4.85 & 9.41 & 22.86 & 1.94 & 4.71 \\
9 & 4.22 & 9.05 & 14.62 & 2.14 & 3.46 \\
10 & 4.29 & 7.20 & 12.00 & 1.68 & 2.80 \\
11 & 4.36 & 7.32 & 14.08 & 1.68 & 3.23 \\
12 & 4.53 & 11.47 & 24.38 & 2.53 & 5.38 \\
13 & 4.02 & 10.28 & 15.42 & 2.56 & 3.83 \\
14 & 2.91 & 7.20 & 12.00 & 1.68 & 2.80 \\
15 & 5.27 & 13.41 & 24.38 & 2.75 & 5.38 \\
\hline & L/B & L/H & L/T & B/H & B/T \\
\hline
\end{tabular}

\section{Pengolahan Data}

Perhitungan ukuran pokok kapal diawali dengan pemberian batasan/owner requirement untuk kapal ikan 30 Gross Tonnage (GT) dengan kecepatan kapal 12 knot. Owner requirement ini akan digunakan untuk memperoleh variabel desain kapal berupa panjang kapal keseluruhan ( $\left.\mathrm{L}_{\mathrm{OA}}\right)$, lebar $(\mathrm{B})$, tinggi sarat $(\mathrm{T})$, dan tinggi geladak $(\mathrm{H})$, dan $\mathrm{Cb}$ (coefisien block). Selanjutnya dilakukan pengolahan data secara statistik melalui proses regresi polinomial kuadratik antara ukuran pokok utama kapal pembanding dengan Gross Tonnage (GT) kapal (berdasarkan hasil data survei lapangan) [5].

Hasil perhitungan regresi polinomial kuadratik ukuran pokok utama kapal terhadap nilai (GT) adalah sebagaimana diperlihatkan pada gambar 2 sampai dengan gambar 5. 


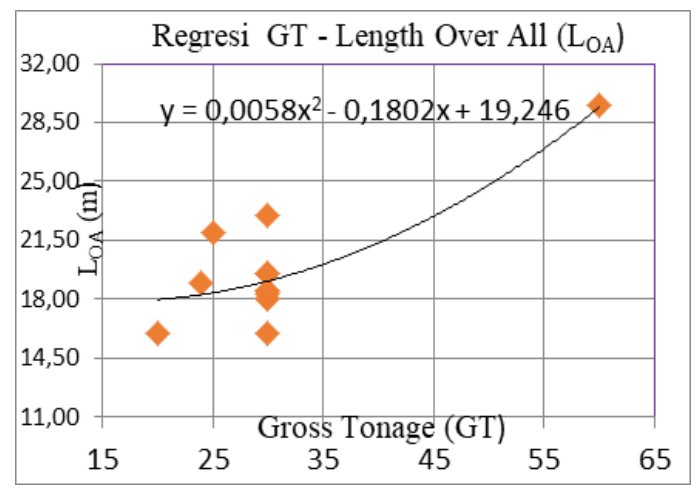

GAMBAR 2. Penentuan Ukuran Panjang Kapal (LoA)

Pada gambar 2 adalah penentuan ukuran panjang kapal (LOA) menggunakan regresi polonial kuadratik yang merupakan fungsi antara panjang kapal (arah vertikal) dan Gross Tonnage $30 \mathrm{RT}$ (arah horizontal) dengan persamaan $\mathrm{y}=0.0058 \mathrm{X}^{2}-0.18 \mathrm{X}+19.24$ yang diperoleh dari data kapal pembanding melalui program excel solver.

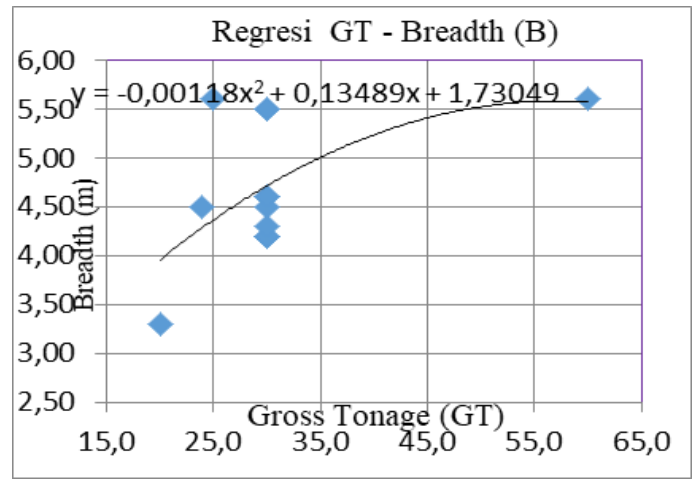

GAMBAR 3 Penentuan Ukuran Lebar Kapal (B)

Pada gambar 3 adalah penentuan ukuran lebar kapal (B) menggunakan regresi polonial kuadratik yang merupakan fungsi antara lebar kapal (arah vertikal) dan Gross Tonnage 30 $\mathrm{RT}$ (arah horizontal) dengan persamaan $\mathrm{y}=0.0011 \mathrm{X}^{2}+0.135 \mathrm{X}+1.73$ yang diperoleh dari data kapal pembanding melalui program excel solver.

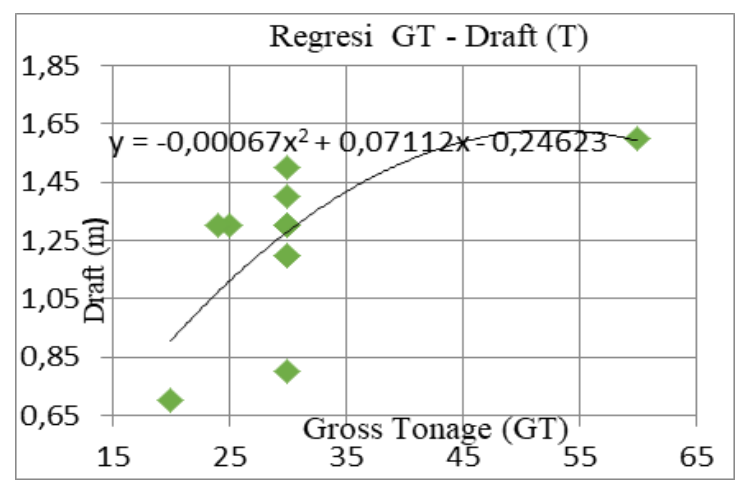

GAMBAR 4. Penentuan Ukuran Draft Kapal (T)

Pada gambar 4 adalah penentuan ukuran tinggi sarat air (T) menggunakan regresi polonial kuadratik yang merupakan fungsi antara tinggi sarat kapal (arah vertikal) dan Gross Tonnage $30 \mathrm{RT}$ (arah horizontal) dengan persamaan y $=0.00067 \mathrm{X}^{2}+0.071 \mathrm{X}-$ 0.24 yang diperoleh dari data kapal pembanding melalui program excel solver. 


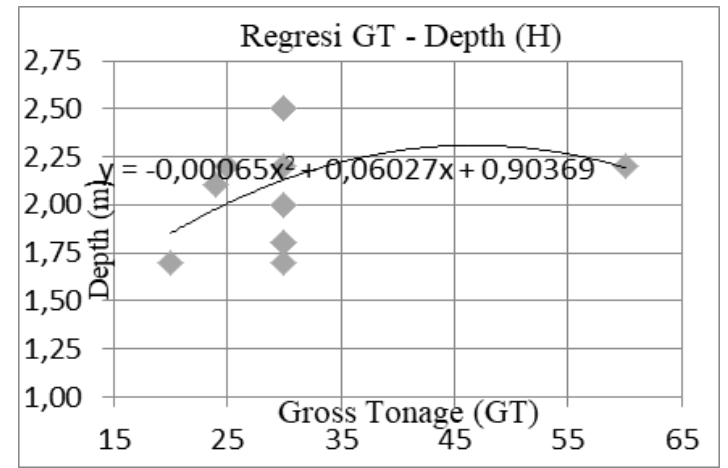

GAMBAR 5. Penentuan Ukuran Tinggi Kapal $(\mathrm{H})$

Pada gambar 5 adalah penentuan ukuran tinggi geladak $(\mathrm{H})$ menggunakan regresi polonial kuadratik yang merupakan fungsi antara tinggi geladak (arah vertikal) dan Gross Tonnage $30 \mathrm{RT}$ (arah horizontal) dengan persamaan $\mathrm{y}=0.00065 \mathrm{X}^{2}+0.067 \mathrm{X}+0.9 \mathrm{yang}$ diperoleh dari data kapal pembanding melalui program excel solver.

Berdasarkan hasil dari regresi polinomial kuadratik ukuran pokok utama kapal terhadap nilai (GT), diperoleh nilai ukuran utama awal (initial value) adalah panjang (Loa) = $19,06(\mathrm{~m})$, lebar $(B)=4.72(\mathrm{~m})$, tinggi $(\mathrm{H})=2.13(\mathrm{~m})$, sarat $(\mathrm{T})=1.28(\mathrm{~m})$ serta $\mathrm{Cb}=$ 0.55 (ditentukan).

\section{Proses Optimasi Dengan Excel Solver}

Proses optimasi yang dilakukan dengan menggunakan microsoft excel add-in solver [6]. Langkah pengerjaan optimasi dilakukan untuk mendapatkan desain kapal operasional yang memenuhi nilai aspek yaitu meminimalkan tenaga mesin utama (minimizing the main engine power). Adapun langkah-langkah proses optimasi dengan menggunakan Microsoft Excel add-in Solver meliputi antara lain:

- Variabel desain (design variables)

Nilai awal (initial value) variabel desain adalah yang dihasilkan dari proses regresi polinomial, yaitu panjang $($ Loa $)=19.06(\mathrm{~m})$, lebar $(\mathrm{B})=4.72(\mathrm{~m})$, tinggi $(\mathrm{H})=2.13$ $(\mathrm{m})$, sarat $(\mathrm{T})=1.28(\mathrm{~m}), \mathrm{Cb}=0.55$ (ditentukan). Parameter desain (design parameters) yaitu $\mathrm{GT}=30$, kecepatan $(\mathrm{Vk})=12$ knot.

- Batasan desain (design constraints) meliputi variabel dari ukuran utama kapal dengan kondisi sarat $0.7 \leq \mathrm{T} \leq 1.60 \mathrm{~m}$, coefficien block $(\mathrm{Cb}) 0.5 \leq \mathrm{Cb} \leq 0.6$. Rasio antara variabel desain $2.90 \leq \mathrm{L} / \mathrm{B} \leq 5.25,7.20 \leq \mathrm{L} / \mathrm{H} \leq 13.40,12 \leq \mathrm{L} / \mathrm{T} \leq 24.40,2.80 \leq$ $\mathrm{B} / \mathrm{T} \leq 4,1.65 \leq \mathrm{B} / \mathrm{H} \leq 2.75$. Margin desain: 27.5 ton $\leq \mathrm{DWT} \leq 28.0$ ton, stabilitas awal $\mathrm{GM}_{\mathrm{T}}=\mathrm{KB}+\mathrm{BM}_{\mathrm{T}}-\mathrm{KG} \geq 0.07 \mathrm{~B}$. Dimana $\mathrm{GM}_{\mathrm{T}}$ tinggi metasenter melintang $(\mathrm{m}), \mathrm{KB}$ jarak keel ke titik tekan (m), $\mathrm{BM}_{\mathrm{T}}$ radius metasenter melintang (m), KG jarak keel ke titik berat kapal (m) dan B lebar kapal (m).

- Perhitungan propertis desain (Design properties) meliputi, perhitungan displacement dilakukan sesuai persamaan $\Delta=\mathrm{L} \times \mathrm{B} \times \mathrm{T} \times \mathrm{Cb} \times \rho$, dimana $\mathrm{L}$ panjang antara garis air tegak (m), B lebar kapal (m), T tinggi sarat (m), Cb koefisien blok dan $\rho$ berat jenis air laut $\left(\mathrm{t} / \mathrm{m}^{3}\right)$. Perhitungan light ship weight dilakukan dengan menghitung berat $W_{\mathrm{S}}$ $=\mathrm{W}_{\mathrm{H}}+\mathrm{W}_{\mathrm{SPS}}$, dimana $\mathrm{W}_{\mathrm{H}}=\mathrm{K} \times \mathrm{V}^{0.5} \times \Delta$ dan $\mathrm{W}_{\mathrm{SPS}}=6 \% \mathrm{~W}_{\mathrm{H}}$ dimana $\mathrm{W}_{\mathrm{H}}$ berat lambung kapal (ton), $\mathrm{W}_{\text {SPS }}$ berat superstructure (ton), $\mathrm{K}$ koefisien berat, $\mathrm{V}$ kecepatan kapal (m/det) dan $\Delta$ displasemen (ton) [7]. Sementara berat peralatan $\mathrm{W}_{\mathrm{E}}=\mathrm{KV}^{0.9} \Delta^{3 / 4}$, dimana $\mathrm{K}$ koefisien berat, V kecepatan kapal (m/det), $\Delta$ displacement (ton). Serta perhitungan berat mesin $\mathrm{W}_{\mathrm{M}}=\mathrm{KV}^{3} \Delta^{2 / 3}$ dimana $\mathrm{K}$ adalah koefisien berat permesinan, $\mathrm{V}$ adalah kecepatan kapal (knot) dan $\Delta$ displacement (ton). Sehingga LWT $=\mathrm{W}_{\mathrm{S}}+$ $\mathrm{W}_{\mathrm{M}}+\mathrm{W}_{\mathrm{E}}$, dimana $\mathrm{W}_{\mathrm{S}}$ berat seluruh baja kapal (ton), $\mathrm{W}_{\mathrm{M}}$ berat peralatan kapal (ton) dan $\mathrm{W}_{\mathrm{E}}$ berat permesinan (ton).

Untuk perhitungan dead weight sesuai persamaan DWT $=\Delta-$ LWT, dimana $\Delta$ displacement (ton) dan LWT light weight tonnage (ton). Perhitungan kecepatan (V 
$\mathrm{m} /$ det). Perhitungan kecepatan kapal sesuai persamaan $\mathrm{V}=0.514 \times(\mathrm{V})$, dimana $\mathbf{V}$ kecepatan kapal (knot). Sedangkan untuk perhitungan froude number sesuai persamaan $\mathrm{F}_{\mathrm{n}}=\mathrm{V} /\left(\mathrm{g} \times \nabla^{1 / 3}\right)^{0.5}$ dimana $\mathrm{V}$, kecepatan kapal $(\mathrm{m} / \mathrm{det})$, g, percepatan gravitasi $\left(\mathrm{m} / \mathrm{det}^{2}\right)$ dan $\nabla$ displasemen volume $\left(\mathrm{m}^{3}\right)$. Untuk perhitungan Freeboard menggunakan kurva regresi [8], yaitu, $\mathrm{Fb}=-0.016944 \times \mathrm{L}+22.80 \times \mathrm{L}-691.69$ dimana $\mathrm{L}$ panjang antara garis tegak $(\mathrm{m})$.

Perhitungan trim sesuai persamaan [9] diantaranya Midship coefficient $\mathrm{Cm}=\{1+(1-$ $\mathrm{Cb}) \times 3.5-1\}$ dimana $\mathrm{Cb}$ koefisien blok. Longitudinal prismatic coefficient $\mathrm{Cp}=\mathrm{Cb} /$ $\mathrm{Cm}$, waterplane coefficient, Amid $=-13.5+(19.4 \times \mathrm{Cp})$ dimana $\mathrm{Cp}$ koefisien prismatik. Amid $\mathrm{LCB}=\mathrm{Amid} \mathrm{LCB}(\%) \times \mathrm{L}$. Longitudinal center of buoyancy $\mathrm{LCB}=$ $0.5 \times \mathrm{L}-$ Amid, longitudinal center of gravity $\mathrm{LCG}=-0.15+\mathrm{LCB}$, dimana LCB Longitudinal center of buoyancy $(\mathrm{m})$ dan $\mathrm{L}$ panjang antara garis air tegak $(\mathrm{m})$.

Vertical center of buoyancy above base line $\mathrm{KB}=0.09-0.3 \mathrm{~cm}-0.1 \times \mathrm{Cb} \times \mathrm{T}$, dimana $\mathrm{Cm}$ koefisien midship, Cb koefisien blok dan $\mathrm{T}$ tinggi sarat $(\mathrm{m})$. Transverse waterplane inertia coefficient $\mathrm{CI}=0.1216 \times \mathrm{Cwp}-0.041$. Longitudinal water plane inertia coeff $\mathrm{CI}_{\mathrm{L}}=0.35 \times \mathrm{Cwp}+0.14$ dimana Cwp koefisien garis air. Moments of inertia of the water plane relative to transverse axis $\mathrm{I}_{\mathrm{T}}=\mathrm{CI} \times \mathrm{L} \times \mathrm{B}^{3}$, dimana $\mathrm{CI}$ transverse waterplane inertia coefficient, L panjang antara garis air tegak $(\mathrm{m}), \mathrm{B}$ adalah lebar kapal (m). Moments of inertia of the waterplane relative to longitudinal axis $\mathrm{I}_{\mathrm{L}}=\mathrm{CI}_{\mathrm{L}} \times \mathrm{B} \times \mathrm{L}^{3}$ dimana $\mathrm{CI}_{\mathrm{L}}$ longitudinal waterplane inertia coeff, $\mathrm{B}$ adalah lebar kapal (m) dan L panjang antara garis air tegak (m). Longitudinal metacenteric radius $\mathrm{BM}_{\mathrm{L}}=\mathrm{IL} / \nabla \mathrm{BML}$, dimana $\mathrm{I}_{\mathrm{L}}$ Moments of inertia of the waterplane relative to longitudinal axis $\left(\mathrm{m}^{4}\right), \nabla$ displacement $\mathrm{kapal}\left(\mathrm{m}^{3}\right)$. Longitudinal metacentric height $\mathrm{GM}_{\mathrm{L}}=\mathrm{CI}_{\mathrm{L}} \times \mathrm{L}^{2} /(\mathrm{Cb} \times \mathrm{T})$ dimana $\mathrm{CI}_{\mathrm{L}}$ Longitudinal water plane inertia coeff, $\mathrm{L}$ panjang antara garis air tegak $(\mathrm{m}), \mathrm{Cb}$ koefisien blok dan $\mathrm{T}$ tinggi sarat $(\mathrm{m})$. Trim $(\mathrm{Ta}$ $-\mathrm{TF})=(\mathrm{LCG}-\mathrm{LCB}) \times \mathrm{L} / \mathrm{GM}_{\mathrm{L}}$ dimana $\mathrm{LCG}$ longitudinal center of gravity $(\mathrm{m}), \mathrm{LCB}$ longitudinal center of buoyancy $(\mathrm{m})$, L panjang antara garis air tegak $(\mathrm{m})$ dan $\mathrm{GM}_{\mathrm{L}}$ tinggi metasenter memanjang $(\mathrm{m})$.

Perhitungan stabilitas awal sesuai persamaan berikut [9], Center of gravity $\mathrm{KG}=1+$ $(0.53 \times \mathrm{H})$, dimana $\mathrm{H}$ tinggi geladak $(\mathrm{m})$. Center of Buoyancy $\mathrm{KB}=0.9-0.3 \times \mathrm{Cm})-$ $(0.1 \times \mathrm{Cb})$, dimana $\mathrm{Cm}$ koefisien midship dan Cb koefisien blok. Radius metasenter ke buoyancy $\mathrm{BM}_{\mathrm{T}}=(0.085 \mathrm{Cb}-0.002) \times \mathrm{B}^{2} / \mathrm{T} \times \mathrm{Cb}$, dimana $\mathrm{Cb}$ koefisien blok, $\mathrm{B}$ lebar kapal $(\mathrm{m})$ dan T tinggi sarat $(\mathrm{m})$. Tinggi metacenter $\mathrm{GM}_{\mathrm{T}}=\mathrm{BMT}+\mathrm{KB}-(1.03 \times \mathrm{KG})$ dimana $\mathrm{BM}_{\mathrm{T}}$ Radius metasenter ke buoyancy (m), KB Center of Buoyancy (m) dan KG Center of gravity (m).

Untuk menghitung hambatan kapal dengan menggunakan metode Holtrop. dimana hambatan total teridiri atas tiga komponen hambatan, yaitu Viscous resistance (hambatan kekentalan); Appendages resistance (hambatan karena bentuk kapal); Wave making resistance (hambatan gelombang). Hambatan total menurut sesuai persamaan [10], $R_{\mathrm{T}}=1 / 2 \rho \times \mathrm{Vs}^{2} \times \mathrm{S}_{\text {tot }}\{\mathrm{CF}(1+\mathrm{k}) \mathrm{CA}+\mathrm{Ra} / \mathrm{w} \times \mathrm{W}\}$, dimana $\rho$ berat jenis air $\left(\mathrm{t} / \mathrm{m}^{3}\right)$, Vs kecepatan $(\mathrm{m} / \mathrm{s}), \mathrm{S}_{\text {tot }}$ luas permukaan basah badan kapal (m), CF koefisien gesek, (1+k) koefisien faktor bentuk, CA ship correlation allowance, $\mathrm{R}_{\mathrm{W}} / \mathrm{W}$ koefisien tahanan gelombang dan $\mathrm{W}$ sebagai gaya keatas pada kapal atau bouyancy $(\mathrm{N})$. Sehingga $S_{\text {tot }}=S+S_{\text {app }}$, dimana $\mathrm{S}$ wetted surface area (WSA) berdasarkan hidrostatik (m) dan $S_{\text {app }}$ luasan dari daerah tonjolan kemudi, boss dan propeller (m).

Fungsi Objektif (Objectif function) yang dioptimumkan pada proses optimasi ini adalah meminimalkan tenaga mesin utama (minimizing the main engine power). Hasil optimasi microsoft excel add-in solver didapatkan nilai hambatan (resistance) sebesar $17.93 \mathrm{kN}$ dengan minimizing the main engine effective power sebesar $110,669 \mathrm{~kW}$ (150.47 Hp). Dengan memasukan data parameter desain variables, desain propertis dan didapatkan fungsi obkejectif kedalam (optimasi_Holtrop) sesuai gambar.5 maka diperoleh set desain ukuran utama kapal, yakni panjang $($ Loa $)=21(\mathrm{~m})$, lebar $(\mathrm{B})=4$ $(\mathrm{m})$, tinggi $(\mathrm{H})=1.80(\mathrm{~m})$, sarat $(\mathrm{T})=1(\mathrm{~m}), \mathrm{Cb}=0.5$ 


\section{KESIMPULAN}

Berdasarkan pembahasan dan hasil dari kegiatan penelitian berupa preliminary design penentuan ukuran pokok kapal ikan 30 GT berbahan fiberglass, diperoleh ukuran pokok kapal yang optimum, yakni: Panjang $($ Loa $)=21(\mathrm{~m})$, Lebar $(B)=4(\mathrm{~m})$, Tinggi $(\mathrm{H})=1.8(\mathrm{~m})$, Sarat $(\mathrm{T})=1(\mathrm{~m})$ dan $\mathrm{Cb}=0.5$. Penentuan ukuran pokok kapal menggunakan metode optimasi, dengan bantuan software optimasi holtrop (microsoft Excel add-in solver). Minimizing the main engine effective power sebesar $110.67 \mathrm{~kW}$ (150.47 Hp).

\section{UCAPAN TERIMA KASIH}

Penelitian tentang preliminary design ukuran pokok kapal ikan fiberglass 30 GT dapat dilakukan secara baik atas bantuan dan kerja sama galangan kapal fiberglass PT. Pruskoneo Putra Mandiri. Oleh karena itu ucapan terima kasih yang tulus kepada pimpinan dan segenap karyawan.

\section{DAFTAR PUSTAKA}

[1] A. Marasabessy and S. Siagian, "Analisis Keretakan Pelat Zona Lambung Kapal Berbahan Fiber Glass," Kapal, vol. 13, no. 3, p. 99, 2016.

[2] T. Tarno, "Estimasi Model Regresi Linier Dengan Metode Median Kuadrat Terkecil," J. SAINS DAN Mat., vol. 15, no. 2, pp. 69-72, 2007.

[3] Z. Zong, Z. Hong, Y. Wang, and H. Hefazi, "Hull form optimization of trimaran using self-blending method," Appl. Ocean Res., vol. 80, no. June 2017, pp. 240247, 2018.

[4] A. Papanikolaou, Ship design: Methodologies of preliminary design. 2014.

[5] "Diesel Outboard Motors," vol. 11, no. 2, 2014.

[6] A. H. Muhammad, . Baharuddin, and H. Hasan, "Desain Freeboard Minimum Terhadap Keselamatan Dan Pengurangan Biaya Operasional Kapal Perikanan 30 Gt Di Perairan Sulawesi (Studi Kasus Km Inka Mina 759),” J. Ilmu dan Teknol. Kelaut. Trop., vol. 10, no. 2, p. 409, 2018.

[7] S. N. Matafi, H. V. Dien, and F. P. T. Pangalila, "Simulasi pengaruh trim terhadap stabilitas kapal purse seine," J. Ilmu Dan Teknol. Perikan. Tangkap, vol. 2, pp. 13$18,2015$.

[8] Tri Nanda Citra Bangun, Ali Muntaha, and Sunardi, "Stabilitas Kapal Ikan Katamaran Sebagai Pengganti Kapal Purse Seine di Kabupaten Pamekasan Madura Jawa Timur," vol. I, no. 1, pp. 13-21, 2017.

[9] M. A. Azis, B. H. Iskandar, and Y. Novita, "KAJIAN DESAIN KAPAL PURSE SEINE TRADISIONAL DI KABUPATEN Oleh: Mahasiswa Program Pasca Sarjana Departemen PSP FPIK IPB," Albacore, vol. I, no. 1, pp. 69-76, 2017.

[10] S. Gudmundsson, General Aviation Aircraft Design. Applied methods and procedures. 2014. 